\title{
O panorama do ensino da Ética no Brasil: da ditadura aos dias atuais
}

\author{
The panorama of Ethics teaching in Brazil: from the dictatorship to the present day \\ El panorama de la enseñanza de Ética en Brasil: de la dictadura hasta la actualidad
}

\author{
MAYRA MARQUES DA Silva GUALTIERI-KAPPANN* \\ AlONSO BEZERRA DE CARVALHO**
}

\begin{abstract}
$\diamond$
RESUMO

O panorama brasileiro da educação e também o do ensino da Ética reflete e perpassa as mudanças históricas, sociais, políticas e econômicas do nosso país. Este artigo pretende discutir como o ensino da Ética vem sendo tratado em nossas escolas, em especial no estado de São Paulo, do período da ditadura aos dias atuais. Analisaremos as medidas governamentais deste período e as políticas públicas implementadas na educação neste contexto social e político e que buscaram responder às solicitações da sociedade por uma educação que privilegiasse o desenvolvimento ético do ser humano. Para atingirmos este objetivos, realizamos uma pesquisa bibliográfica e documental que apresentaremos ao leitor, problematizando algumas destas questões na atualidade.
\end{abstract}

Palavras-chave: Educação. Ensino. Ética.

\begin{abstract}
The Brazilian panorama of education and also the Ethics teaching reflects and runs through historical, social, political and economic changes of our country. This article discusses how the teaching of Ethics is being addressed in our schools, especially in the state of São Paulo, from the period of the dictatorship to the present day. We analyze government measures this period and public policies implemented in education in this social and political context and sought to answer the demands of society for education that give preference ethical development of human beings. To achieve this objective, we conducted a bibliographic and documentary research we will present to the reader, discussing some of these issues today.
\end{abstract}

Keywords: Education. Teaching. Ethics.

\section{RESUMEN}

El panorama de la educación brasileña y también de la enseñanza de la Ética refleja y se ejecuta a través de cambios históricos, sociales, políticos y económicos de nuestro país. Este artículo describe cómo se está abordando la enseñanza de la Ética en las escuelas, sobre todo en el estado de São Paulo, de la época de la dictadura hasta nuestros días. Analizaremos las medidas del gobierno de este período y las políticas públicas implementadas en la educación en este contexto social y político que buscaban responder a las demandas de la sociedad para la educación que dan preferencia a el desarrollo ético de los seres humanos. Para lograr este objetivo, se realizó una investigación bibliográfica y documental que presentaremos al lector, discutiendo algunas de estas cuestiones en la actualidad.

Palavras clave: Educación. Enseñanza. Ética.

\footnotetext{
*Doutora em Educação, Professora do Departamento de Psicologia Experimental e do Trabalho da UNESP/Assis. Membro dos Grupos de Estudos e Pesquisas em Educação, Ética e Sociedade (GEPEES), do Núcleo de Estudos de Violência e Relações de Gênero (NEVIRG) e do Grupo de Pesquisa em Desenvolvimento Sociomoral de Crianças e Adolescentes, cadastrados no CNPq. Financiamento: CAPES. E-mail: $<$ mayragualtieri@hotmail.com>.

**Livre-docente, Professor do Departamento de Educação da Unesp/Assis e do Programa de Pós-Graduação em Educação da Unesp/Marília. Líder do Grupo de Estudo e Pesquisa em Educação, Ética e Sociedade (GEPEES), cadastrado no CNPq. E-mail: <alonsoprofessor@yahoo.com.br>.
} 
O panorama brasileiro da educação e também o do ensino da Ética reflete e perpassa as mudanças histórias, sociais, políticas e econômicas do nosso país. Este artigo pretende discutir como o ensino da Ética vem sendo tratado em nossas escolas, em especial no estado de São Paulo, do período da ditadura aos dias atuais. Para atingirmos este objetivos, realizamos uma pesquisa bibliográfica e documental que apresentaremos ao leitor, problematizando algumas destas questões na atualidade.

Consideramos a Ética, assim como suas mudanças, como parte da história humana e do processo de autocriação e autotransformação do homem que se manifesta de várias maneiras, desde as formas materiais da existência até suas formas espirituais, aqui inclusa a vida moral e a educação. A Ética apresenta ainda uma íntima relação com outras ciências que estudam o desenvolvimento humano e a estruturação das sociedades, como a Psicologia, a Sociologia, a Política e a Educação (VASQUEZ, 1982).

A dimensão ética do viver e do conviver humano, implicada na nossa necessidade ou possibilidade de sustentar a integridade da vida individual e coletiva, nos leva a refletir sobre o que devemos, podemos, queremos e de como coordenamos estas questões em função do coletivo, da convivência e da manutenção da integridade social. Uma das ferramentas que dispomos para isto é a racionalidade que, no plano das ações, nos torna capazes de refletir sobre elas e, para além das ações tão somente guiadas por paixões ou impulsos, nos torna capazes de as transmutar em ações transformadoras conscientes, um agir intencional em busca de mudanças no ambiente que nos favoreçam ou aos outros e que nos ajudem a lidar de modo mais adequado com as exigências do viver em sociedade (CORTELLA, 2011).

Percebemos assim que a Ética é inseparável da atividade prática dos homens, e, portanto, é material e espiritual (VASQUEZ, 1982). Ao pensarmos na estruturação do ensino da Ética na educação brasileira, temos que levar em consideração que em cada momento histórico, ela expressa as concepções filosóficas de homem e de mundo de seu tempo e do tipo de agente moral que se deseja formar para a vida em sociedade, não sendo possível, portanto, pensar o panorama do ensino da ética no Brasil sem levar em considerações os fatores sociais e históricos que nele incidem.

Para Romano (2004), muitas atitudes éticas foram assumidas por povos e classes sociais de modo irrefletido ao longo da história porque foram aprendidas desde a infância. Na prática, isto tanto pode se traduzir como uma atitude de respeito e consideração pelo outro, uma vivência de aprendizado com a cultura e experiência de vida do outro, como pode se traduzir em uma repetição do processo de alienação frente às figuras de autoridade $e$ uma repetição de velhos costumes e hábitos sem qualquer ato de reflexão ou crítica sobre isto.

O modo como o ensino da Ética se estruturou no Brasil do período da ditadura aos dias atuais expressa muitas destas atitudes éticas irrefletidas pela sociedade e alguns equivocados posicionamentos governamentais em termos de educação. Para Cortella (2011) vivemos uma crise educacional de longa data, com raízes estruturais históricas que se manifestam de diferentes formas e em conjunturas específicas. É o caso do confronto existente entre a adoção de um ensino laico ou o de caráter religioso ou confessional; da questão do conflito entre conteúdos, metodologias e adequação a novas ideologias nas diferentes escolas; do impasse da democratização do acesso à educação; do dilema da progressão continuada e da aprovação automática; das peculiaridades e problemas enfrentados pela educação de jovens e adultos e das diferenças entre o ensino público e o privado. Isso sem contar a questão da desigualdade na formação dos educadores, defasagem de salário, extensas jornadas de trabalho, e outras questões que se aliam a problemas de difícil enfrentamento como a evasão escolar e outros motivos episódicos de crise, como as longas greves nas instituições públicas de ensino, dentre muitos outros fatores problemáticos que poderíamos analisar na educação brasileira.

A esta realidade se somam os efeitos das diferentes ideologias políticas dos governantes e a deficiência de políticas públicas eficazes e de longo alcance para a educação. $O$ fatores anteriormente descritos vêm de séculos passados e adentraram este novo século ainda mais profícuos e vigorosos, o que torna esta crise ainda mais atual e relevante nos dias atuais. Para Cortella (2011), eles evidenciam um deliberado projeto de exclusão e dominação social que precisa ser revogado, sob o peso de permanecermos sempre presos ao maniqueísmo mercantil ou na disfarçada delinquência e negligência estatal com os fatores concretos e subjetivos da educação brasileira.

Compreendemos que o ser humano depende fortemente dos processos educacionais e da educação para sua sobrevivência, quer consideremos a educação como a vivencial ou espontânea, aquela realizada no dia-a-dia, na convivência e no aprender fazendo, quer a educação intencional ou proposital, organizada pelas instituições sociais como a escola. Estas instituições sociais - escola, família, igreja, mídia, mercado profissional entre outros são ainda o canal de conservação e inovação dos valores da sociedade em seu determinado tempo histórico e os guardiões dos fundamentos e dos poderes políticos e epistemológicos que governam e sustentam a vida em sociedade (CORTELLA, 2011). Desta forma, o modo como o ensino da Ética vem sendo tratado na educação brasileira afeta diretamente os cidadãos que formamos e 
os posicionamentos políticos e sociais que tomamos em nossa vida em sociedade.

\section{O PANORAMA BRASILEIRO E O ENSINO DA ÉTICA NO PERÍODO DA DITADURA}

Há cerca de cinquenta anos, somente $30 \%$ da população moravam na cidade, o que afetava de modo diferente instituições como as escolas, os serviços de saúde, habitação, trabalho, segurança e infraestrutura urbana. Do ponto de vista da produção, esta se baseava nos grandes latifúndios, situação que não exigia grandes níveis de escolarização e especialização dos trabalhadores. $\mathrm{O}$ acelerado processo de urbanização, transferiu milhares de brasileiros das áreas rurais, predominantemente sem escolas, para as cidades e suas instituições (CORTELLA, 2011).

Com a aceleração da industrialização e a concentração crescente dos meios de produção e dos trabalhadores, as cidades sofreram um abrupto inchaço, evidenciado na urbanização crescente e não planejada das cidades. Aliados a fatores como ausência de reforma agrária efetiva e acúmulo de incentivos fiscais aos grandes proprietários de terra, o cultivo de alimentos nas pequenas propriedades foi perdendo espaço e empurrando os pequenos lavradores para as cidades e as indústrias. Este cenário trouxe novas demandas para as cidades, e estas não estavam preparadas nem receberam recursos à altura de suas necessidades. Este fatores contribuíram para o colapso dos setores básicos de atenção à população e à uma crescente ocupação deles pelo setor privado da economia (CORTELLA, 2011).

Entre 1945 e 1964 as instituições democráticas e a economia passaram a se fortalecer no país, em detrimento das demandas sociais que permaneceram negligenciadas pelo Estado. A partir de 1964, o modelo econômico implantado no país passou a privilegiar a produção capitalista industrializada. Isto fez com que os recursos públicos e os esforços políticos privilegiassem os investimentos em mais infraestrutura nas cidades, além de estradas para escoar a produção, hidrelétricas para produzir energias, meios de comunicação de massa mais eficazes, além de tornar necessário um volume maior de capital que pudesse financiar a aquisição do novas tecnologias e equipamentos necessários à produção. Este capital foi conseguido em sua maioria através de empréstimos estatais e privados no exterior, o que levou a um endividamento do país e uma maior retirada de recursos financeiros que fizeram falta nos setores sociais, como saúde e educação (CORTELA, 2011).

$\mathrm{Na}$ educação a evidência desta crise se expressou na demanda explosiva por vagas nas escolas, sem que houvesse um preparo da rede para isso. Aliada à fragilidade e insuficiência de estrutura física nas escolas, vivenciamos um empobrecimento didático e pedagógico das unidades escolares, o ingresso massivo de educadores sem formação adequada e a consequente queda na qualidade do ensino, das condições reais da escola e de trabalho e renda dos professores, o que degradou ainda mais o frágil sistema educacional público existente no país (CORTELA, 2011).

Neste cenário, houve uma centralização excessiva dos recursos orçamentários em poder do Estado, o que favoreceu o controle político das instâncias normatizadoras como a escola, além do favorecimento da corrupção e desperdício no setor público e o fortalecimento dos setores privados (CORTELLA, 2011).

Na educação, caras escolas particulares passaram a prometer e a oferecer um ensino de melhor qualidade do que o do setor público, elitizando o acesso à educação de qualidade no país, concentrando a mão de obra de professores melhor qualificados e criando um verdadeiro regime separatistas entre pobres e ricos nas escolas (CORTELLA, 2011).

Apesar do populismo do discurso político vigente na época, vários movimentos sociais e partidos de esquerda começaram a surgir no Brasil e a reivindicar mudanças. E, em 1964, alegando uma ameaça de revolução comunista, os militares tomam o poder no Brasil, instaurando um regime de ditadura que perdurou até 1984 . Este regime instaurou severas restrições à liberdade democrática no país, o que incluía a extinção do pluripartidarismo, a instauração do regime bipartidário, da censura e do rígido controle do que era ensinado nas escolas e universidades, controle sobre livros, músicas e todo tipo de material didático nas escolas, além da perseguição aos intelectuais, em especial aos considerados de esquerda, prisão e tortura aos opositores. Nesta época, muitos intelectuais e políticos importantes pediram exílio político no exterior.

Sobre o legado da ditadura para a educação pública brasileira, Cunha (2014) aponta dois fatores principais. O primeiro é que a educação passou a ser tratada em função da simbiose Estado-capital. Empurrada pela crescente demanda pela elevação dos requisitos educacionais necessários ao emprego, diversos cursos e instituições de diferentes níveis, em especial, superior, foram criados, tanto no setor público, como no privado. Em 21 de novembro de 1968 (menos de um mês antes da promulgação do Ato Institucional n. 5, o AI 5) foi promulgada a Lei n. 5.537, que criou o Fundo Nacional de Desenvolvimento da Educação (FNDE). Este fundo tinha a finalidade de reunir e canalizar recursos financeiros de diversas fontes para o financiamento de projetos de ensino que poderiam ser apresentados tanto pelos governos federal, estaduais e municipais, como por estabelecimentos privados. O governo daria o dinheiro e 
as escolas dariam uma compensação pelo recurso recebido através da reserva de vagas para bolsas de estudo, bolsas de manutenção ou de estágio, distribuídas pelo próprio FNDE. Desta forma, fundos públicos, criados por decisão estatal para financiarem a expansão das redes públicas, acabaram sendo estratégicos para a manutenção e a expansão do setor privado da educação, que se beneficiou largamente das deficiências das redes públicas.

O outro legado da ditadura foi o uso da educação como instrumento de regeneração moral do indivíduo e da sociedade. Mesmo antes da ditadura, no início da década de 1960, advinha da Escola Superior de Guerra uma corrente de pensamento que defendia a inclusão dos valores morais e espirituais entre os Objetivos Nacionais Permanentes. De acordo com Arruda (1980, apud CUNHA, 2014), o conteúdo subjacente a esta corrente era o enfrentamento do marxismo materialista, tido como uma ameaça às tradições democráticas e cristãs e responsável pelo declínio nos padrões de comportamento social, que deveria ser combatido pelo ensino da Moral e do Civismo. Após o golpe de Estado, esta concepção gerou a ideia de que o "saneamento moral da sociedade constituiria uma condição indispensável para o desenvolvimento" (ARRUDA, 1980, p. 158 apud CUNHA, 2014, p. 368).

Assim, em 12 de setembro de 1969, acatando a proposta da Associação dos Diplomados da Escola Superior de Guerra, o governo militar baixou o DecretoLei n. 869, tornando obrigatória a inserção da disciplina Educação Moral e Cívica nos currículos de todos os níveis e modalidades de ensino do país, tanto no setor público quanto no privado. No ensino superior, por exemplo, ela se chamou Estudos de Problemas Brasileiros (CUNHA, 2014). Estas medidas foram tentativas governamentais de responder às solicitações por uma educação que privilegiasse o desenvolvimento ético do ser humano através da implantação de novas políticas públicas em educação, mas, neste contexto social e político, a escola se tornou um instrumento de dominação e doutrinação política, permanecendo distante do objetivo de uma educação realmente moral e cívica das pessoas.

Os programas que deveriam ser seguidos nesta disciplina foram elaborados pelo Conselho Federal de Educação (criado em 1961), com a colaboração da Comissão Nacional de Moral e Civismo (CNMC), indicada pelo presidente da República. Segundo Cunha (2014), a Educação Moral e Cívica se apoiava nas tradições nacionais e tinha as seguintes finalidade: a defesa do princípio democrático, através da preservação do espírito religioso, defendendo a dignidade da pessoa humana e do amor à liberdade com responsabilidade e sob a inspiração de Deus; a preservação, o fortalecimento e a projeção dos valores espirituais e éticos da nacionalidade; o fortalecimento da unidade nacional e do sentimento de solidariedade humana; o culto à pátria, aos seus símbolos, tradições, instituições e grandes vultos de sua história; o aprimoramento do caráter, com apoio na moral, na dedicação à família e à comunidade; a compreensão dos direitos e deveres dos brasileiros e o conhecimento da organização sociopolítico-econômica do país; o preparo do cidadão para o exercício das atividades cívicas, com fundamento na moral, no patriotismo e na ação construtiva visando o bem comum; o culto da obediência à lei, da fidelidade ao trabalho e da integração na comunidade.

Para Rezende (2001), este programa, assim como os conteúdos dos livros didáticos de Educação Moral e Cívica e as demais reformas da educação no período militar, eram parte das estratégias do governo para controlar todos os aspectos da vida social, política, econômica, cultural e educacional das pessoas, na tentativa de homogeneizar valores e ações favoráveis ao projeto de governo de "integração nacional", ao mesmo tempo em que representavam seu intento de convencer os cidadãos de que as ações em prática beneficiariam a todos e expressariam os ideais democráticos mais elevados da nação.

Assim, "As vicissitudes da transição para a democracia levaram a Educação Moral e Cívica a uma longa agonia, ao contrário do fim do Estado Novo, quando ela foi extinta imediatamente após a deposição de Vargas" (CUNHA, 2014, p. 371).

Somente vinte anos depois, em 1984, tivemos a volta do regime democrático no Brasil, através da primeira eleição direta para presidente da República, em um país já adoecido em suas questões sociais e economicamente fragilizado pelas altas inflações e instabilidade econômica.

\section{O ENSINO DO ENSINO DA ÉTICA NOS DIAS ATUAIS}

Em 1988, nossa Constituição foi promulgada, mas, este aparente retorno político à democracia pouco se expressou nas condições sociais da população da época, marcada pela desigualdade econômica e social e a fragilidade das instituições públicas no atendimento às necessidades de saúde, emprego e educação.

A partir de 1988, a Constituição Nacional elenca a educação como um direito social básico e inalienável do cidadão brasileiro. Diz a Constituição Brasileira em seu Capítulo II, Dos Direitos Sociais, Artigo 6웅

São direitos sociais a educação, a saúde, a alimentação, o trabalho, a moradia, o lazer, a segurança, a previdência social, a proteção à maternidade e à infância, a assistência aos desamparados, na forma desta Constituição (BRASIL, 1988. Redação dada pela Emenda Constitucional no 64, de 2010). 
Advindo das mudanças políticas e da nova Constituição do país, o antigo Conselho Federal da Educação, criado em 1961, foi extinto em 1994, através da criação do Conselho Nacional de Educação (MP no 661, de 18/10/94, convertida na Lei no 9.131/95). Este Conselho Nacional de Educação (CNE) persiste até os dias atuais e é o órgão colegiado integrante do Ministério da Educação (MEC). Ele tem a finalidade de colaborar na formulação da Política Nacional de Educação e exercer atribuições normativas, deliberativas e de assessoramento ao Ministro de Estado da Educação, no desempenho das funções e atribuições do poder público federal em matéria de educação.

Segundo o Ministério da Educação (MEC, 1997), o professor da atualidade, ao atuar como um profissional a quem compete conduzir o processo de reflexão que possibilitará ao aluno autonomia para eleger seus valores, tomar posições e ampliar seu universo de conhecimento, deverá ter discernimento para não transmitir seus valores, crenças e opiniões como princípios ou verdades (MEC, 1997).

Neste contexto, em 1997, foi lançado pelo Ministério da Educação (MEC) uma coleção de livros intitulada Os Parâmetros Curriculares Nacionais, ou PCN's, como ficaram conhecidos. Eles se configuravam como os parâmetros oficiais do governo federal de referências para os Ensinos Fundamental e Médio de todo o país e objetivava garantir a todas as crianças e jovens brasileiros, mesmo em locais com condições socioeconômicas desfavoráveis, o direito de usufruir do conjunto de conhecimentos reconhecidos como necessários para o exercício da cidadania, estabelecendo uma referência curricular e apoiando a revisão e/ou elaboração da proposta curricular dos estados ou das escolas integrantes dos sistemas de ensino, contribuindo para a transformação de objetivos, conteúdos e didática do ensino.

Nos PCN's estavam contidos os temas transversais, ou seja, aqueles oriundos do conceito de transversalidade, definido pelo documento como aquele que diz respeito à possibilidade de se estabelecer, na prática educativa, uma relação entre aprender na realidade e da realidade de conhecimentos teoricamente sistematizados (aprender sobre a realidade) e as questões da vida real (aprender na realidade e da realidade). Este conceito se liga à ideia de interdisciplinaridade - a existência de uma relação entre disciplinas - e questiona a segmentação entre os diferentes campos de conhecimento produzida por uma abordagem e/ou uma visão compartimentada da realidade, própria da estruturação disciplinar rígida dos currículos (MEC, 1997).

Esperava-se, com a eleição dos temas transversais, que interdisciplinaridade e transversalidade se alimentassem mutuamente na prática pedagógica. Almejava-se que o tratamento das questões trazidas pelos temas transversais promovesse uma compreensão abrangente dos diferentes objetos de conhecimento, bem como a percepção da implicação do sujeito de conhecimento na sua produção, superando a dicotomia entre ambos e abrindo espaço para a inclusão de saberes extra-escolares. Isto facilitaria a construção de um sistema de referências e significados que pudessem ser construídos na realidade dos alunos, dando um sentido social aos procedimentos e conceitos próprios das áreas convencionais, visando a superação do aprender apenas pela necessidade escolar (MEC, 1997).

Sendo assim, a Ética constava como tema transversal no Ensino Fundamental (v. 8.2) e no Ensino Médio (v. 10.2). No Ensino Fundamental a Ética se apresentava ao lado de outros temas como Meio Ambiente, Saúde, Pluralidade Cultural e Orientação Sexual. No Ensino Médio era ladeada por temas sobre Meio Ambiente, Saúde, Orientação Sexual e Trabalho e Consumo. Cada um destes temas possuía um volume destinado à sua apresentação e propostas que deveriam ser, prioritariamente, trabalhadas em sala de aula por professores de todas as disciplinas, tanto quanto fosse possível adequá-las ao conteúdo ministrado e projetos desenvolvidos junto aos alunos e à comunidade.

Em 2006, retomando as questões e críticas levantadas pela divulgação dos PCN's como parâmetros oficiais e que resultou em ampla discussão com as equipes técnicas dos Sistemas Estaduais de Educação, professores e alunos da rede pública e representantes da comunidade acadêmica desde 2004, não só no sentido de aprofundar a compreensão sobre pontos que mereciam esclarecimentos, como também de atender às necessidades e às expectativas das escolas e dos professores na estruturação do currículo para o Ensino Médio, apontando e desenvolvendo indicativos que pudessem oferecer alternativas didáticopedagógicas para a organização do trabalho pedagógico nas escolas, foram elaboradas as Orientações Curriculares para o Ensino Médio (OCN's) que substituíram os PCN's enquanto documentos oficiais de referência do governo federal, em relação ao que se esperava que fossem trabalhados dentro do currículo oficial a ser discutido em cada estado (MEC, 2006).

O objetivo oficial deste material foi descrito como para contribuir para o diálogo entre professor e escola sobre a prática docente, considerando a qualidade da escola como condição essencial de inclusão e democratização das oportunidades no Brasil, e o desafio de oferecer uma educação de qualidade para a inserção do aluno, o desenvolvimento do país e a consolidação da cidadania como uma tarefa de todos, além de se constituírem como os parâmetros oficiais que serviriam de base para a elaboração das propostas curriculares de cada estado. As OCN's não objetivavam se configurar como um manual 
ou uma cartilha a ser seguida, mas um instrumento de apoio à reflexão do professor a ser utilizado em favor do aprendizado (MEC, 2006).

Neste mesmo contexto histórico, além da publicação das OCN's, outras medidas para garantir a democratização do acesso e as condições de permanência na escola durante as três etapas da educação básica - educação infantil, ensino fundamental e médio -, foram tomadas pelo governo federal, além da elaboração de novas propostas, como a Proposta de Emenda à Constituição (PEC) do Fundeb (Fundo de Manutenção e Desenvolvimento da Educação Básica e de Valorização dos Profissionais da Educação) e outras ações de fortalecimento do ensino médio, como o Prodeb (Programa de Equalização das Oportunidades de Acesso à Educação Básica) e a implementação do PNLEM (Programa Nacional do Livro do Ensino Médio). A Secretaria de Educação Básica do MEC passou a publicar ainda livros para o professor, a fim de apoiar o trabalho científico e pedagógico do docente em sala de aula e forte ênfase foi dada à institucionalização do Ensino Médio integrado à educação profissional, buscando romper com a dualidade que historicamente separou os estudos preparatórios para a educação superior da formação profissional no Brasil. Neste momento, a formação inicial e continuada também passou a ser oferecida em parceria com as Secretarias de Educação e Instituições de Ensino Superior (IES) para a formação dos professores, com a implantação do PróLicenciatura, do ProUni (Programa Universidade para Todos) e da Universidade Aberta do Brasil (MEC, 2006).

Nas OCN's, a Ética e outros temas a ela relacionados, saíram da categoria de temas transversais e passaram a fazer parte das orientações curriculares para as disciplinas específicas de Filosofia e Sociologia. Estas orientações estão contidas no volume 3 das Orientações curriculares para o ensino médio, que trata das Ciências humanas e suas tecnologias (MEC, 2006).

Cabe ressaltar, que neste momento de reformulação dos currículos nacionais, disciplinas como a Sociologia e a Filosofia passam a fazer parte dos currículos nacionais a partir de então. Este é um marco histórico importante, pois, no caso da Filosofia, esta havia deixado de ser obrigatória em 1961 (Lei no 4.024/61) e excluída do currículo escolar oficial em 1971 (Lei no 5.692/71), criando-se um hiato em termos de seu amadurecimento como disciplina. E, embora na década de 90, a Lei no 9.394/96 (lei que estabelece as diretrizes e bases da educação nacional) tenha determinado que ao final do ensino médio o estudante deveria "dominar os conteúdos de Filosofia e Sociologia necessários ao exercício da cidadania" (artigo 36), nem por isso a Filosofia passou a ter um tratamento de disciplina, como os demais conteúdos, mantendo-se no conjunto dos temas ditos transversais.
Assim, a rediscussão dos parâmetros curriculares para a disciplina trouxe novo fôlego para a sua consolidação entre os componentes curriculares do ensino médio, retomando seu lugar na formação dos estudantes, com especial ênfase dada pelas OCN's para o caráter inter e transdisciplinar da Filosofia. Percurso semelhante passou a Sociologia como disciplina, foi obrigatória no currículo entre os anos de 1931 e 1942 e, mais especificamente, após o ano de 1937, deixando de ser obrigatória a partir de 2001, por veto presidencial.

Assim, embora a noção dos temas transversais como tarefa conjunta dos professores de todas as disciplinas, aí inclusas a formação Ética, ainda façam parte da formação dos professores pesquisados neste trabalho, a ênfase atual das diretrizes governamentais para a escola é no cumprimento do currículo oficial de cada estado que deve ser organizado segundo as OCN's.

No caso específico do Estado de São Paulo, um currículo oficial foi proposto em 2008 pela Secretaria da Educação e tornado oficial em 2011, através da elaboração de documentos oficiais, na coleção documental Currículo do Estado de São Paulo (SÃO PAULO, 2011). Além de especificar as disciplinas que se tornaram obrigatórias nas escolas de todo o estado, o documento apresenta os princípios orientadores do currículo para uma escola capaz de promover as competências indispensáveis ao enfrentamento dos desafios sociais, culturais e profissionais do mundo contemporâneo. Ele contempla algumas das principais características da sociedade do conhecimento e das pressões que a contemporaneidade exerce sobre os jovens cidadãos, propondo princípios orientadores para a prática educativa. Ao priorizar a competência de leitura e escrita, o Currículo define a escola como espaço de cultura e de articulação de competências e de conteúdos disciplinares (SÃO PAULO, 2011).

Além desse documento básico curricular, há um segundo conjunto de documentos, com orientações para a gestão do Currículo na escola intitulado Caderno do Gestor que se dirige especialmente às unidades escolares e aos professores coordenadores, diretores, professores coordenadores das oficinas pedagógicas e supervisores. Esse material não trata da gestão curricular em geral, mas tem a finalidade específica de apoiar o gestor para que ele seja um líder capaz de estimular e orientar a implementação do Currículo nas escolas públicas estaduais de São Paulo. Há ainda outros materiais disponibilizados pela Secretaria da Educação sobre o tema da gestão, aos quais as equipes gestoras podem recorrer para apoiar seu trabalho. A ênfase desse segundo conjunto de documentos é garantir que a Proposta Pedagógica, que organiza o trabalho nas condições singulares de cada escola, seja um recurso efetivo e dinâmico para assegurar 
aos alunos a aprendizagem dos conteúdos e a constituição das competências previstas no Currículo (SÃO PAULO, 2011).

Espera-se também que a aprendizagem resulte da coordenação de ações entre as disciplinas, do estímulo à vida cultural da escola e do fortalecimento de suas relações com a comunidade. Para isso, os documentos reforçam e sugerem orientações e estratégias para a formação continuada dos professores (SÃO PAULO, 2011).

O Currículo ainda se completa com um conjunto de documentos dirigidos especialmente aos professores e aos alunos: os Cadernos do Professor e do Aluno, organizados por disciplina/série e ano/bimestre. Neles, são apresentadas Situações de Aprendizagem para orientar o trabalho do professor no ensino dos conteúdos disciplinares específicos e a aprendizagem dos alunos. Esses conteúdos, habilidades e competências são acompanhados de orientações para a gestão da aprendizagem em sala de aula e para a avaliação e a recuperação. Oferecem também sugestões de métodos e estratégias de trabalho para as aulas, experimentações, projetos coletivos, atividades extraclasse e estudos interdisciplinares (SÃO PAULO, 2011).

\section{CONCLUSÕES}

Observamos que nos documentos oficiais atuais há uma preocupação com o cumprimento do currículo escolar em todas as esferas da Educação. Não consideramos que tal empenho seja necessariamente um equívoco, apenas gostaríamos de deixar aqui nosso apontamento sobre uma Educação atual baseada no domínio da episteme e das regras a serem seguidas pela escola, na inflexibilidade em suas propostas, com pouco espaço para a individualização dos processos e estratégias de aprendizagem, bem como das atividades pelo professor, baseada no cumprimento de rígidas regras, prazos, conteúdos e atividades préprogramadas pelo Estado para a totalidade de escolas, alunos e realidades. Este modelo de educação, como tal, corre o risco de desconsiderar aspectos psíquicos, sociais e históricos de cada aluno, cada escola, bem como o mérito das competências do professor de fazer tais adequações e de livremente, utilizar seus conhecimentos técnicos, experiência e criatividade no planejamento de suas atividades com os alunos, estreitando cada vez mais o espaço vivencial para a autonomia e o questionamento, quer na prática docente, quer na vivência estudantil.

Vivemos um processo de grande esforço governamental para democratização do ensino e a universalização de seu acesso. Tal discurso da política pública brasileira dos últimos vinte anos se relaciona com as recomendações de organismos internacionais que insistem nas ações para superar a crise de eficiência, eficácia e produtividade do sistema. O discurso atual é de que o principal problema a ser sanado é desencontro entre o sistema educacional e as necessidades do mercado de trabalho. A saída da crise, para esta orientação política, está em tratar a educação e o conhecimento como eixos da transformação produtiva com equidade, e como fator de competitividade das nações e das empresas (CEPAL; UNESCO, 1995).

Em relação a essa concepção, Coelho (2008) pondera que é necessário considerar que a educação pode estar sendo transformada em uma mera possibilidade de consumo individual, variando segundo o mérito e a capacidade dos consumidores, o que pode acabar por the negar a condição de direito social. E um estudo sobre os vinte anos de avaliação da educação básica no Brasil, afirma que a discussão dos problemas da educação básica no Brasil tem sido marcada, pela ampla divulgação das informações produzidas pelo sistema de avaliação externa, em larga escala, centralizada e com foco no rendimento do aluno e no desempenho dos sistemas de ensino.

Concordamos com Cortella (2011) que não parece ser plausível falar em democracia e democratização da educação se isto não se traduzir em uma escola pública que objetive uma educação da classe trabalhadora com uma sólida base científica, formação crítica de cidadania e solidariedade de classe social. Uma educação nesta perspectiva social implica em um retorno às necessidades da quase totalidade da população, o que inclui as necessidades de conhecimento e informação necessários às demandas cotidianas, como redução do analfabetismo, escolarização universal e manutenção do emprego, mas não exclui as possibilidades de crítica social e transformação coletiva da existência (CORTELLA, 2011).

Acreditamos, juntamente com autores como Romano (2004), que no Brasil há um desprezo governamental pela educação pública, do ensino fundamental ao superior. Embora diversos investimentos tenham sido feitos, em especial nos últimos governos, as políticas públicas em educação, embora tenham aumentado o acesso às escolas em todos os níveis de escolaridade, ainda estão longe de contemplar a igualdade e a justiça em termos de educação de quantidade e qualidade a todos. Muitos esforços têm sido feitos por educadores, pesquisadores, políticos, iniciativa privada e população em geral neste sentido, mas olhando à nossa volta, percebemos que é bem possível que em um país de desigualdades e injustiças sociais e econômicas, a educação, assim como outros setores da vida social, ainda reflita o mesmo panorama. 


\section{REFERÊNCIAS}

ALMEIDA, Laurinda Ramalho. Diretrizes para a formação de professores: uma releitura. In: ALMEIDA, Laurinda Ramalho; PLACCO, Vera Maria Nigro de Souza. As relações interpessoais na formação de professores. São Paulo: Loyola, 2002. p. 44-63.

BRASIL. Constituição Federal. Texto completo de 1988. Disponível em: < http://www.senado.gov.br/legislacao/const/ con1988/CON1988_05.10.1988/art_6_.shtm>. Acesso em: 01 set. 2014.

BRASIL. Ministério da Educação (MEC). Orientações curriculares para o ensino médio. Vol. 3. Ciências humanas e suas tecnologias. Brasília: Secretaria de Educação Básica, 2006. 133 p. Disponível em: <http://portal.mec.gov.br/seb/arquivos/ pdf/book_volume_03_internet.pdf $>$. Acesso em: 26 abr. 2015.

BRASIL. Ministério da Educação (MEC). Parâmetros Curriculares Nacionais. Apresentação dos temas transversais - Ética. Brasília, 1997. Disponível em: <http://portal.mec.gov. br/seb/arquivos/pdf/livro081.pdf>. Acesso em: 01 fev. 2015.

COELHO, Maria Inês de Matos. Vinte anos da educação básica no Brasil aprendizagens e desafios. Ensaio: aval. pol. públ. Educ., Rio de Janeiro, v. 16, n. 59, p. 229-258, abr./jun. 2008.
CORTELlA, Mário Sérgio A escola e o conhecimento: fundamentos epistemológicos e políticos. 14. ed. São Paulo: Cortez, 2011.

CUNHA, Luiz Antônio. O legado da ditadura para a educação brasileira. Educação \& Sociedade, Campinas, v. 35, n.127, p. 357-377. 2014. Disponível em: <http://www.scielo.br/scielo. php? script $=$ sci_arttext\&pid=S0101-73302014000200002\&lng $=\mathrm{pt} \& \operatorname{lng}=\mathrm{pt}>$ Acesso em: 01 jul. 2015 .

GORDON, Thomas. Teacher effectiveness training. Nova Iorque: Randon House, 2003.

REZENDE, Maria José. A ditadura militar no Brasil: repressão e pretensão de legitimidade 1964-1984. Londrina: UEL, 2001.

ROMANO, Roberto. As faces da Ética. In: MIRANDA, Danilo Santos (Org.). Ética e cultura. São Paulo: Perspectiva, 2004. p. $39-50$.

SÃO PAUlO (ESTADO). Secretaria da Educação. Currículo do Estado de São Paulo: Ciências da Natureza e suas tecnologias. 2. ed. atual. São Paulo, 2011. 152 p.

Submetido em 30/07/2015

Aprovado em 08/06/2016 